\title{
Juvenile Salmon Migration Observations in the Discovery Islands and Johnstone Strait in 2018 Compared to 2015-2017
}

\author{
Brett Johnson ${ }^{1}$, Julian C.L. Gan ${ }^{1}$, Sean C. Godwin ${ }^{4,6}$, Martin Krkosek ${ }^{5,6}$, and Brian P.V. Hunt ${ }^{1,2,3}$ \\ ${ }^{1}$ Hakai Institute, P.O. Box 309, Heriot Bay, BC, VOP 1HO, Canada \\ ${ }^{2}$ Institute for the Oceans and Fisheries, University of British Columbia, Vancouver, BC, V6T 1Z4, Canada \\ ${ }^{3}$ Department of Earth, Ocean and Atmospheric Sciences, University of British Columbia Vancouver, BC, V6T 1Z4, \\ Canada \\ ${ }^{4}$ Earth to Ocean Research Group, Department of Biological Sciences, Simon Fraser University, Burnaby, BC, V5A \\ 1S6, Canada \\ ${ }^{5}$ Department of Ecology and Evolutionary Biology, University of Toronto, Toronto, ON, M5S 3B2, Canada \\ ${ }^{6}$ Salmon Coast Field Station, Simoom Sound, BC, VOP 1SO, Canada
}

Keywords: salmon, early marine survival, migration dynamics, climate change

Summary

The Hakai Institute Juvenile Salmon Program has been monitoring juvenile salmon migrations in the Discovery Islands and Johnstone Strait since 2015 with the specific purpose to understand how ocean conditions experienced by juvenile salmon during their early marine migration impacts their growth, health and ultimately survival. We found that during the two of the warmest years of sea-surface temperature recorded in British Columbia waters, juvenile sockeye, pink, and chum left the Strait of Georgia one to two weeks earlier than previously. The temporal distribution of sockeye migration timing out of the Strait of Georgia north through the Discovery Islands was skewed right, indicating that many sockeye migrate together in late May and abundance tails off late into June and July. Pink and chum migrations are more protracted, lasting from early May to late July. Our results indicate that juvenile sockeye exit the Strait of Georgia en masse, likely in response to ocean temperature and foraging conditions. This report summarizes migration timing, fish length and weight, sea-louse loads, purse seine catch composition, and ocean temperatures observed from the first four years of this research and monitoring program. Combining key variables from this research program with observations from freshwater and high-seas sampling will provide, for some stocks, a complete account of the conditions salmon experience during their migration from their natal river to the high seas. These measures will further our knowledge of what drives early marine mortality, and better our understanding of how salmon are adapting to climate change.

Introduction

The first months after marine entry are a critical period for juvenile salmon growth (Beamish and Mahnken 2001), which may ultimately be responsible for inter-annual variability and long-term declines in British Columbian salmon stocks (Peterman et al. 2010; Beamish et al. 2012). Two of the leading causes of the decline are the impacts of climate change on marine food web dynamics, and the population level effects of pathogens and predators (Cohen 2012). The Discovery Islands and Johnstone Strait are a region of reduced food availability for migrating juvenile salmon and may act as a bottleneck in their early marine survival (McKinnell et al. 2014). The Hakai Institute Juvenile Salmon Program has been monitoring juvenile salmon migrations in the Discovery Islands and Johnstone Strait (Fig. 1) since 2015 to determine the factors that influence early marine survival of sockeye, pink, and chum salmon (Hunt et al. 2018). This report summarizes migration timing, fish length, parasite loads, species composition, and ocean temperatures observed in 2018 and compares these metrics to our observations between 2015 and 2017. We also compare the past four years of this research and monitoring program to historical observations where possible. These measures provide essential support information for ongoing research into the growth, survival, and the impact of ocean conditions experienced by salmon during their early marine migration through this critical region. We report on the interannual variability of juvenile sockeye, pink, chum, coho, and herring population characteristics in relation to the ocean conditions fish experienced in the Strait of Georgia, Discovery Islands and Johnstone Strait in 2015, 2016, 2017, and 2018. 


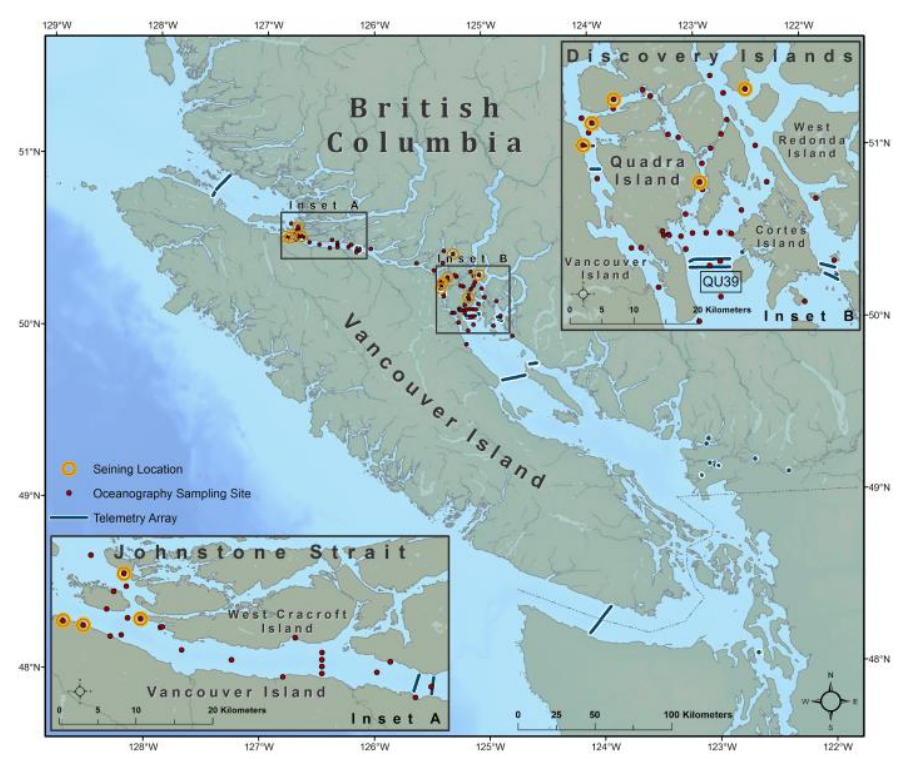

Fig. 1. Juvenile salmon sampling and oceanography stations in the Discovery Islands and Johnstone Strait in 2018.

Methods

\section{Field methods}

See Hunt et al. (2018) for a detailed description of field and lab methods. Briefly, we collected juvenile salmon weekly from the Discovery Islands and Johnstone Strait during their northward migration from the Strait of Georgia to Queen Charlotte Strait near northern Vancouver Island, British Columbia. We sampled from May to July each year, beginning in 2015, using hand-operated purse seine nets (bunt: $27 \mathrm{~m}$ x $9 \mathrm{~m}$ with $13 \mathrm{~mm}$ mesh; tow: $46 \mathrm{~m}$ x $9 \mathrm{~m}$ with $76 \mathrm{~mm}$ mesh) (Groot et al. 1985; Godwin et al. 2015). We sampled near-shore marine habitats where depth was $>10 \mathrm{~m}$ and distance from shore was usually less than $300 \mathrm{~m}$, effectively sampling sockeye (Oncorhynchus nerka), pink (O. gorbuscha) and chum $(O$. keta) salmon, and incidentally capturing coho $(O$. kisutch), Chinook (O. tshawytschya) and Pacific herring (Clupea pallasii). All animal care complied with Animal Care Guidelines under permit A16-0101. We collected temperature data by deploying a Maestro conductivity, temperature, and depth profiler (RBR Ltd. Ottawa, Canada) to depths > $30 \mathrm{~m}$ at station QU39 (Fig. 1) in the northern Strait of Georgia.

Data Analysis

We report 'study-period anomalies' in relation to the averages from 2015-2018 to characterize interannual variability. Measurements from the Discovery Islands and Johnstone Strait regions of the salmon migration were combined in analyses unless otherwise indicated. We used sites that we sampled in all years for calculations. All analyses were conducted using R (R Core Team 2017).

The aim of the program was initially focused on capturing sockeye and better understanding the ecology of co-migrating sockeye, pink and chum schools. In 2015 and 2016, we focused on capturing sockeye, and only enumerated and sampled pink and chum when we also caught sockeye. In 2017, however, we transitioned to enumerating and sampling pink, chum, and other species even when sockeye were absent. To make consistent observations between years migration timing, catch intensity, and catch proportion statistics for sockeye, pink, and chum are calculated based on seines that captured at least one sockeye.

The peak migration date for each species was estimated by calculating the median date of capture in the Discovery Islands. We favored this approach over a 'catch per unit effort' approach because of the nature of our sampling design. Every year seines were conducted before sockeye arrived and after sockeye disappeared, thus we are confident we effectively capture the vast majority of out-migrating juvenile sockeye. This allowed us to constrain the period over which we calculated cumulative abundance to 1 May-9 July and provided a consistent period to make inter-annual comparisons of migration timing. The Fraser River is an even-year-dominant system for pink salmon, and very few out-migrating pinks are caught in odd years; consequently, only even years were included in the calculation of the pink migration study-period averages.

Catch intensity was calculated to provide a measure of inter-annual abundance for sockeye, pink, and chum. We defined catch intensity as the average number of a species caught when $>1$ of that particular species was caught, and when sockeye were also caught. In effect, catch intensity summarizes the abundance of each species in a community of co-migrating sockeye, pink, and chum salmon. 
Species proportions were calculated by dividing the total number of each species caught by the sum of all species caught that season. Only seines that caught sockeye were used in the calculation of species proportions so that we could make consistent comparisons among years. To test whether fork lengths from 2018 were significantly different than the study-period averages we conducted an independent two-group $t$-test. Fork length distributions were visualized by calculating length frequency distributions using kernel density estimates from fork length data.

The abundances of Caligus clemensi and Lepeophtheirus salmonis sea lice were determined by calculating the mean number of lice on all fish observed, according to the definition in Margolis et al. (1990). Only motile (i.e., pre-adult and adult) stages were included in analyses while nauplius, copepodid, and chalimus life stages were excluded because these juveniles were not enumerated in every year. Sea lice were picked and counted from fish in the laboratory, and a dissecting microscope aided identification. Mean abundance estimates and $95 \%$ confidence intervals were bootstrapped 10,000 times from the counts of lice obtained for each species of louse, respecting the hierarchical nature of observations on sockeye, pink and chum from the same seine, in the Discovery Islands and Johnstone Strait from the past four years.

Ocean temperatures were averaged from the top $30 \mathrm{~m}$ of the water column because juvenile salmon inhabit surface waters in the northern Strait of Georgia and Discovery Islands (Levings and Kotyk 1983; Beamish et al. 2012; Johnson et al. 2018). We measured temperatures at station QU39 in the northern Strait of Georgia in May and June - the period during which salmon migrate through the region. To visualize temperature anomalies a local polynomial regression function from the $R$ 'stats' package called 'loess' (Cleveland et al. 1992; R Core Team 2018) was applied to ocean temperatures from all years to represent the average seasonal temperature trend. Average annual temperatures (in ${ }^{\circ} \mathrm{C}$ ) are used to calculate interannual differences and the number of standard deviations each annual observation is from the study-period average, which allows us to characterize interannual variability.

\section{Results}

Migration timing was similar in 2018 compared to 2015, and 2016 for sockeye, pink, and chum, which were among the earliest migration timings recorded in the Discovery Islands compared to previous measurements (Neville et al. 2016) or indicated by catch-abundances by purse seine or trawl surveys in the northern Strait of Georgia and Discovery Islands (Groot et al. 1985; Preikshot et al. 2012; Neville et al. 2013; Fig. 2). Catch intensity was high for pink and chum, but low for sockeye. Pink and chum fork lengths were longer than the average from 2015-2017, but sockeye fork lengths were shorter than average. There appears to be a pattern of pink and chum length anomalies varying together and sometimes opposite of sockeye. Sea-louse abundance was low in 2018 relative to the previous three years. Sea-surface temperatures in 2018 during the smolt migration period in the northern Strait of Georgia were the warmest recorded between 2015 and 2018.

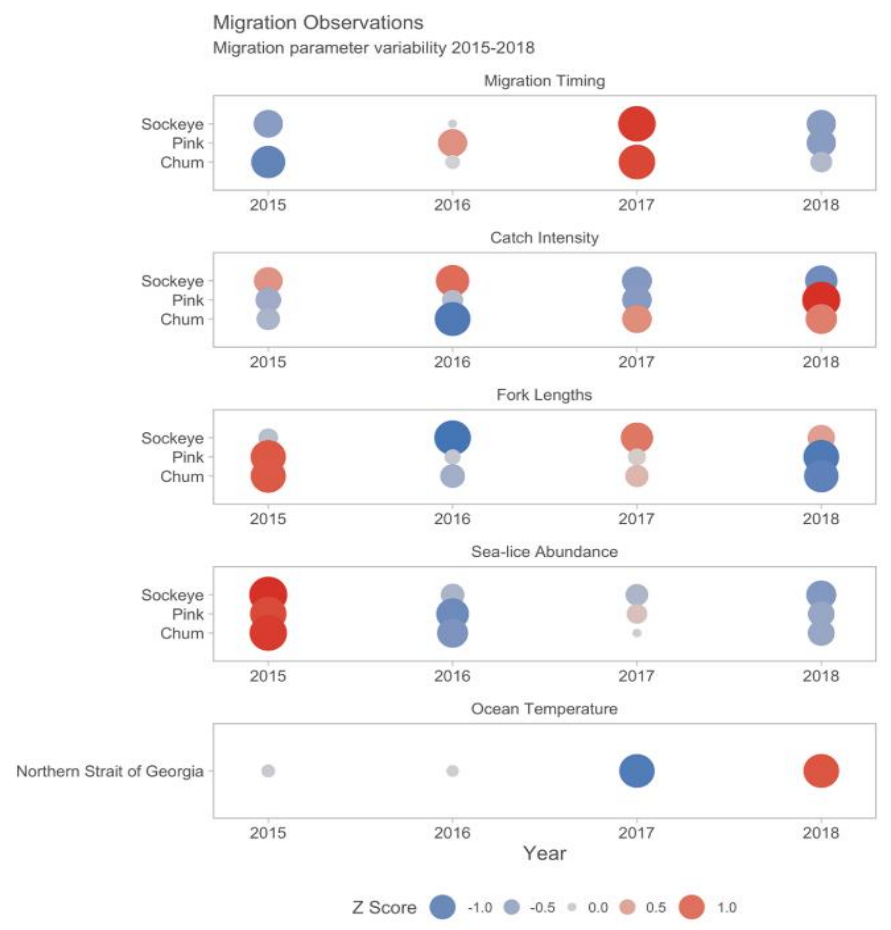

Fig. 2. The number of standard deviations (z score) from the study-period average (2015-2018) for key migration parameters. Size and colour saturation of circles indicates the magnitude of the anomaly. Blue colour indicates less than average; grey indicates average; red indicates greater than average. Peak migration date is based on the median date of fish capture in the Discovery Islands. Length is based on the average fork length from the Discovery Islands and Johnstone Strait combined. Parasite load is the average abundance of all sea-louse species in their motile life stages for both the Discovery Islands and Johnstone Strait regions. Ocean temperature describes the mean ocean temperature in the top $30 \mathrm{~m}$ at station QU39 in the northern Strait of Georgia in May and June. 
Migration timing in the Discovery Islands in 2018 did not differ from the study-period average by more than 5-7 days - the expected accuracy of the calculations - for sockeye, pink, or chum (Fig. 3; Table 1). The peak migration date for sockeye in the Discovery Islands was on May 23, five days earlier than the study-period average of May 28. The peak migration date for pink in the Discovery Islands was on June 12, one day earlier than the average of June 13. The peak migration date for chum in the Discovery Islands was on June 12, three days earlier than the average of June 15.

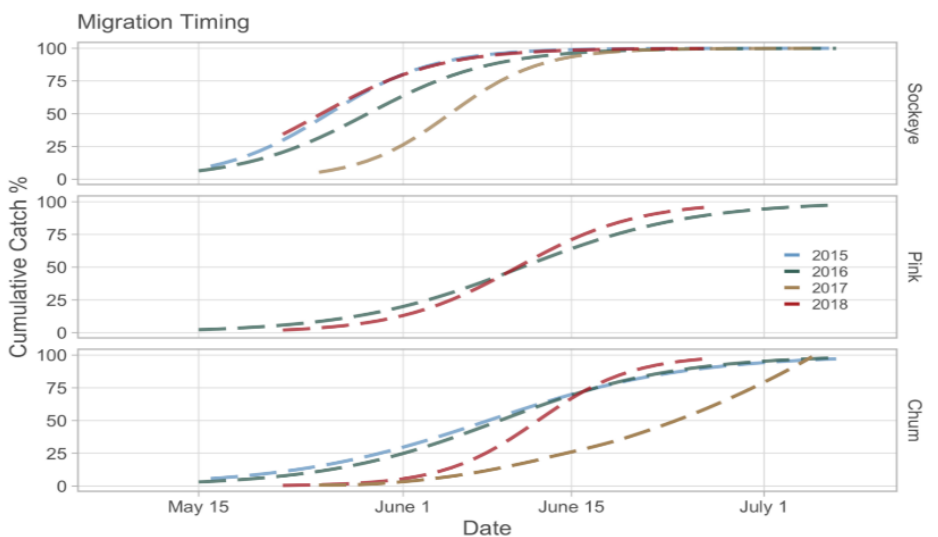

Fig. 3. Cumulative catch of sockeye, pink, and chum, in the Discovery Islands and Johnstone Strait between 2015 and 2017.

Table 1. Migration timing statistics for the cumulative catch of sockeye, pink, and chum salmon in the Discovery Islands in 2018, compared to the study-period average (2015-2018). Q1 is when $25 \%$ of the species passed through the regions, peak date is the median when $50 \%$ passed through, Q3 is 75\%, and Spread is the difference between Peak Date and Q1. The region DI indicates the Discovery Islands and JS indicates Johnstone Strait.

\begin{tabular}{|c|c|c|c|c|c|c|}
\hline Year & Region & Species & Q1 & Peak Date & Q3 & Spread \\
\hline $2015-2018$ & DI & Chum & June 06 & June 15 & June 23 & 8 \\
\hline 2015-2018 & DI & Pink & June 05 & June 13 & June 13 & 9 \\
\hline 2015-2018 & DI & Sockeye & May 26 & May 28 & June 04 & 2 \\
\hline 2015-2018 & JS & Chum & June 11 & June 19 & June 23 & 7 \\
\hline 2015-2018 & JS & Pink & June 16 & June 23 & June 23 & 6 \\
\hline 2015-2018 & JS & Sockeye & June 03 & June 05 & June 18 & 3 \\
\hline 2015 & DI & Chum & June 03 & June 05 & June 22 & 2 \\
\hline 2015 & DI & Sockeye & May 23 & May 23 & June 01 & 0 \\
\hline 2015 & JS & Chum & June 09 & June 16 & June 19 & 7 \\
\hline 2015 & JS & Sockeye & May 26 & May 29 & June 13 & 3 \\
\hline 2016 & DI & Chum & June 02 & June 15 & June 15 & 13 \\
\hline 2016 & DI & Pink & June 02 & June 15 & June 15 & 13 \\
\hline 2016 & DI & Sockeye & May 24 & May 28 & June 04 & 4 \\
\hline 2016 & JS & Chum & June 02 & June 10 & June 24 & 8 \\
\hline 2016 & JS & Pink & June 18 & June 24 & June 24 & 6 \\
\hline 2016 & JS & Sockeye & June 02 & June 03 & June 18 & 1 \\
\hline 2017 & DI & Chum & June 13 & June 26 & July 04 & 13 \\
\hline 2017 & DI & Sockeye & June 05 & June 07 & June 07 & 2 \\
\hline 2017 & JS & Chum & June 20 & June 27 & June 28 & 7 \\
\hline 2017 & JS & Sockeye & June 06 & June 14 & June 21 & 8 \\
\hline 2018 & DI & Chum & June 07 & June 12 & June 20 & 5 \\
\hline 2018 & DI & Pink & June 07 & June 12 & June 12 & 5 \\
\hline 2018 & DI & Sockeye & May 23 & May 23 & June 04 & 0 \\
\hline 2018 & JS & Chum & June 14 & June 21 & June 23 & 7 \\
\hline 2018 & JS & Pink & June 14 & June 21 & June 23 & 7 \\
\hline 2018 & JS & Sockeye & June 07 & June 07 & June 21 & 0 \\
\hline
\end{tabular}


Sockeye catch intensity in 2018 was low relative to previous years and relative to pink and chum in 2018 (Fig. 4). Pink catch intensity in 2018 was the highest of the four years measured. Pink out-migrants are more abundant on even years, the result of the odd-year dominant life-cycle of Fraser River pinks (Heard 1991), but 2018 catches indicate either good production or good survival in the early marine environment for pink salmon relative to 2016 the only other odd-year dominant brood year recorded by the Juvenile Salmon Program.

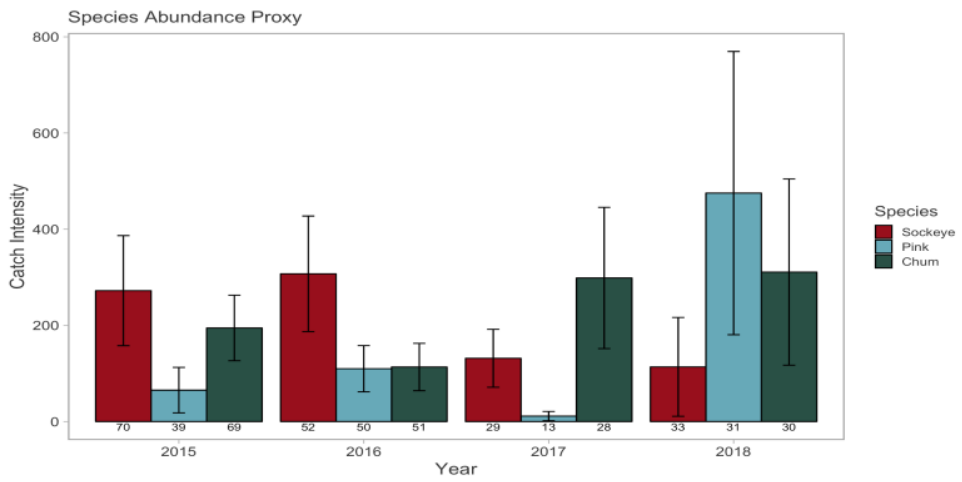

Fig. 4. The catch intensity (our proxy for total abundance) of sockeye, pink, and chum salmon in the Discovery Islands and Johnstone Strait. Numbers under each bar indicate the number of seines in which the species was caught, and error bars indicate the 95 percent confidence region.

Catch proportion was dominated by pink salmon in the Discovery Islands and Johnstone Strait in 2018 making up $51.5 \%$ of the catch (Table 2) while chum made up $32.6 \%$ and sockeye $13.1 \%$ (Fig. 5). This was the first year in the study period in which pink dominated the catch proportion.

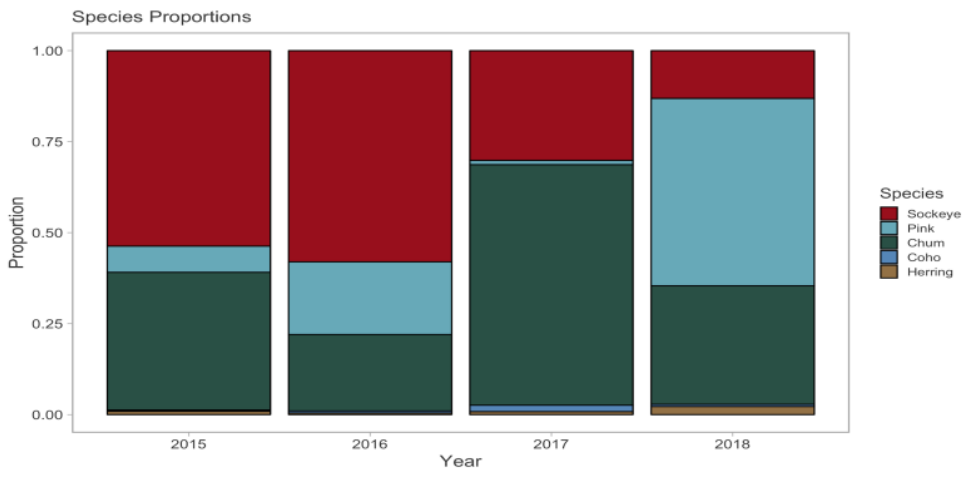

Fig. 5. The annual proportion of fish captured in the Discovery Islands and Johnstone Strait combined.

Table 2. The species proportions of total catch in each year for sockeye, pink, chum, herring, coho, and Chinook.

\begin{tabular}{rrrlrr}
\hline Year & Chum & Coho & Herring & Pink & Sockeye \\
\hline 2015 & 0.378 & 0.003 & 0.009 & 0.072 & 0.537 \\
2016 & 0.210 & 0.006 & 0.005 & 0.200 & 0.580 \\
2017 & 0.661 & 0.018 & 0.008 & 0.012 & 0.301 \\
2018 & 0.326 & 0.006 & 0.022 & 0.515 & 0.131 \\
\hline
\end{tabular}

In 2018, sockeye were longer, pink were shorter, and chum were shorter than their respective study-period averages in the Discovery Islands and Johnstone Strait combined (Fig. 6). Mean sockeye length was $117 \mathrm{~mm}$ (Table 3 ) which is $8 \mathrm{~mm}$ longer than the study-period average $(p<0.0001,95 \%$ CI 5.5-11.2). Average pink lengths were $96 \mathrm{~mm}$, which is $10 \mathrm{~mm}$ shorter than the study-period average $(p<0.0001,95 \%$ CI 11.8-7.2). Chum were on average $104 \mathrm{~mm}$, which is $8 \mathrm{~mm}$ shorter than the study-period average $(p<0.0001,95 \%$ CI 9.9-5.8). Interestingly, sockeye length was, again, the opposite anomaly compared to pink and chum which tend to vary together (Fig. 2). The length frequencies observed here represent the range of fish sizes caught in the nearshore area at the specified times. There are currently no quantitative data available to weight these estimates relative to the proportion of fish that migrate in nearshore versus deep-water habitats, nor is there published data that tests whether population characteristics differ between nearshore and deep-water habitats. These data need to be produced before we can report population-level length frequency estimates. 

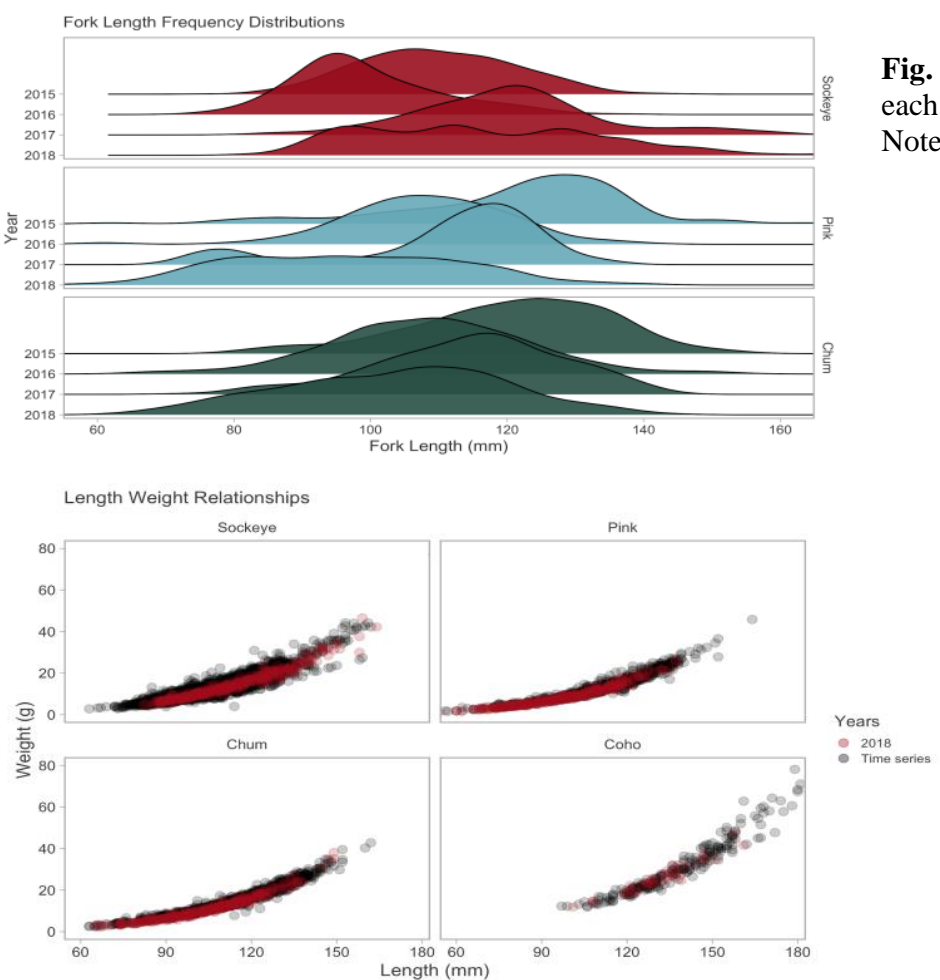

Fig. 6. Distributions of juvenile salmon fork lengths for each year in the Discovery Islands and Johnstone Strait. Note that these distributions contain multiple age classes.
Fig. 7. Length and weight regressions for juvenile salmon caught in the Discovery Islands and Johnstone Strait in 2018 coloured red, compared to all other years in black.

Table 3. Mean fork lengths for each year, species, and region with the $95 \%$ confidence interval (95\% CI). DI stands for Discovery Islands, JS for Johnstone Strait. The column N indicates the number of fish measured.

\begin{tabular}{lrllrl}
\hline Year & Region & Species & N & Fork Length & CI \\
\hline 2015 & DI & Sockeye & 455 & 108.9 & 1.0 \\
2015 & DI & Pink & 47 & 109.6 & 5.5 \\
2015 & DI & Chum & 121 & 115.5 & 2.8 \\
2015 & JS & Sockeye & 334 & 110.7 & 1.2 \\
2015 & JS & Pink & 98 & 127.1 & 2.2 \\
2015 & JS & Chum & 112 & 126.4 & 2.0 \\
2016 & DI & Sockeye & 516 & 97.6 & 0.9 \\
2016 & DI & Pink & 96 & 103.9 & 2.6 \\
2016 & DI & Chum & 124 & 103.3 & 2.6 \\
2016 & JS & Sockeye & 316 & 101.5 & 1.1 \\
2016 & JS & Pink & 94 & 112.6 & 1.9 \\
2016 & JS & Chum & 104 & 115.0 & 2.1 \\
2017 & DI & Sockeye & 260 & 121.3 & 2.0 \\
2017 & DI & Pink & 17 & 90.9 & 8.6 \\
2017 & DI & Chum & 111 & 106.2 & 2.4 \\
2017 & JS & Sockeye & 220 & 119.4 & 1.4 \\
2017 & JS & Pink & 51 & 117.1 & 1.9 \\
2017 & JS & Chum & 151 & 120.7 & 1.6 \\
2018 & DI & Sockeye & 84 & 116.2 & 3.6 \\
2018 & DI & Pink & 205 & 87.8 & 1.8 \\
2018 & DI & Chum & 190 & 97.4 & 2.3 \\
2018 & JS & Sockeye & 85 & 117.6 & 4.4 \\
2018 & JS & Pink & 110 & 112.4 & 1.8 \\
2018 & JS & Chum & 110 & 114.2 & 1.8 \\
\hline
\end{tabular}

Motile sea lice abundance in 2018 was among the lowest recorded in the Discovery study period while Johnstone Strait parasite loads were average (Fig. 8). Notably, no Lepeophtheirus salmonis were detected on sockeye in Johnstone Strait, despite being present in the Discovery Islands. 
Ocean temperature in the top $30 \mathrm{~m}$ of the water column in May and June during the juvenile salmon outmigration at station QU39 in the northern Strait of Georgia was $0.28^{\circ} \mathrm{C}$ warmer on average than they were between 2015-2017 (Fig. 9; Table 1). In the context of the last four years, 2018 was the warmest $30 \mathrm{~m}$ depth-integrated temperature observed in the northern Strait of Georgia in May and June, despite 2015 SST along the B.C. coast breaking records for high temperatures (Chandler et al. 2017). In the past four years, temperatures were well above long-term averages which could make Fig. 9 misleading because if we included temperature data from before 2015 in this analysis, 2018 would appear warmer for more of the year.

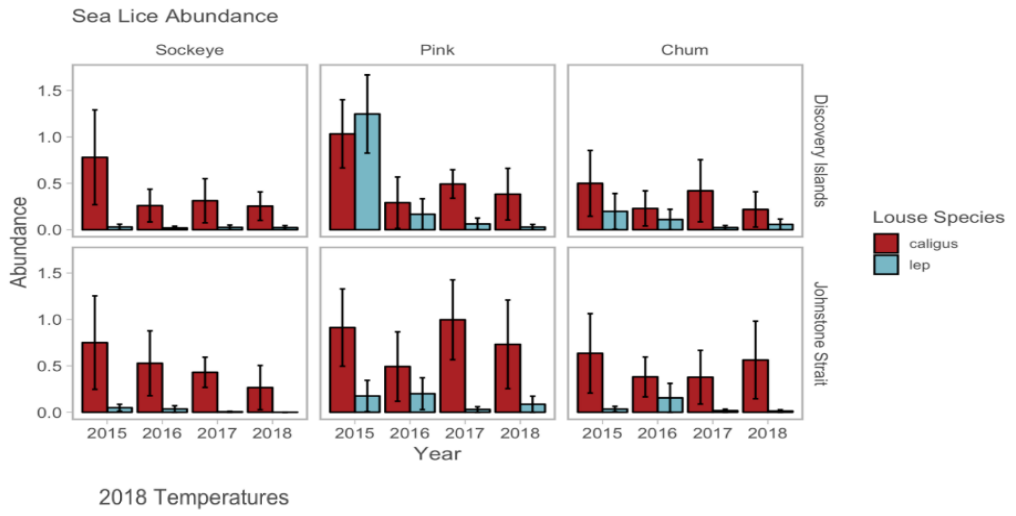

Fig. 8. Lepeoptheirus salmonis (lep), and Caligus clemensi (caligus) sea lice abundance on sockeye, pink, and chum salmon.

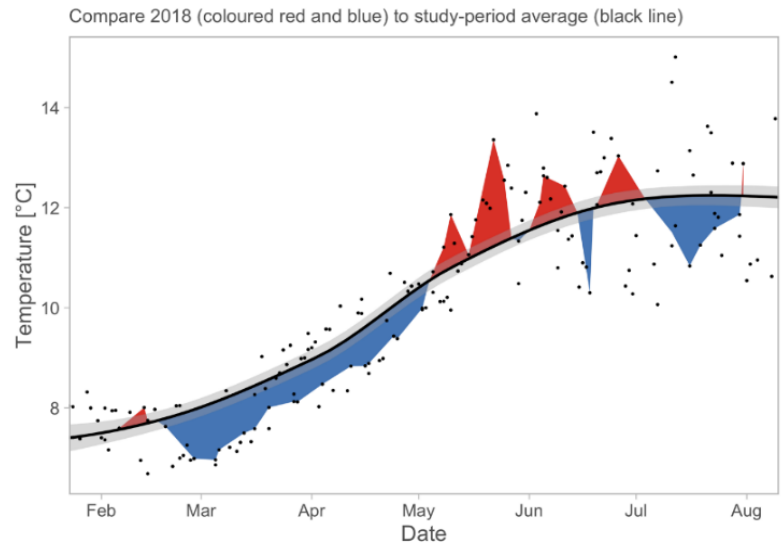

Fig. 9. Thirty-meter depth-integrated ocean temperatures at station QU39 in the northern Strait of Georgia is the solid black line which represents average temperatures from 20152017. Blue areas represent temperatures from 2018 that are below the 2015-2017 average and red areas represent above average temperatures. The shaded grey area is $1 \mathrm{SE}$ of the loess regression. The black dots are the daily minimum and maximum temperatures observed over the study-period.

\section{Discussion}

A period of above-average sea-surface temperatures began in 2013 in British Columbia and the warmest seasurface temperatures observed in British Columbia's time series occurred in 2015 and 2016 when temperatures were more than $1^{\circ} \mathrm{C}$ warmer than normal (Chandler et al. 2018). Temperatures at most stations in $\mathrm{BC}$ were still above average in 2017, but it was not as warm as the previous two years. In 2018, BC sea-surface temperatures were similar to those in 2017. In the northern Strait of Georgia, however, temperature anomalies at Departure Bay and Sentry Shoal were greatest in May and June during the peak salmon migration period (Chandler 2019). This is consistent with what we observed at station QU39 in the northern Strait of Georgia in 2018 - the warmest seasurface temperatures we've observed in our study period. Warmer conditions have been demonstrated to be associated with increased salmon growth rates, however, if anything fish were larger in 2017 when conditions were cooler. This points to factors in addition to temperature that drive growth.

In 2014, a DFO chartered purse seiner measured that $80 \%$ of sockeye passed through the Discovery Islands by June 19. This was considered 'normal' given previous estimates of run timing (Neville et al. 2016). We observed $80 \%$ of sockeye migrate through the Discovery Islands by June 1 in 2015 and 2018, and by June 5 in 2016, which is roughly two and a half weeks earlier than observed in 2014. Sockeye from 2014 and 2017 are from the same genetic-stock cyclic-dominance cohort, and sockeye in 2017 exhibited the latest migration timing of all four run cycles observed, suggesting that this run cycle tends to migrate later than the others. However, it may also be that some other factor, such as cooler sea surface temperature in 2014 and 2017, affected their migration timing. In 2017 Chum migrations were also later than average, and as a result, we did not completely capture the tail end of the migration. It could also be that a higher proportion of chum remained in the Strait of Georgia in 2017. Sockeye 
leave the Strait of Georgia 12-20 days before pink and chum, which may be driven by water temperatures and foraging conditions (LeBrasseur and Parker 1964).

Sockeye migration timing through the Discovery Islands and Johnstone Strait is positively skewed (Johnson et al. 2018), meaning that the tail of the migration distribution is longer on the right and the peak abundance is on the left of the temporal distribution of sockeye abundance over time. The number of days between the $25^{\text {th }}$ and $50^{\text {th }}$ percentile of sockeye catch abundance is short, two days on average, indicating that their northern migration is punctuated (Table 1). Further effort should be directed at identifying the factors that govern this punctuated migration dynamic.

There are better foraging conditions for juvenile salmon found in Queen Charlotte Sound where upwelling nutrients contribute to higher productivity (McQueen and Ware 2006). Sea-surface temperatures in the northern Strait of Georgia in 2017 were the coldest year of those between 2015-2018, which we would expect to be favourable for juvenile salmon forage quality, however the timing of transition to upwelling in Queen Charlotte Strait was late and low in magnitude (Chandler et al. 2018). The degree to which Queen Charlotte Strait and Sound act as a refuge area for juvenile salmon to forage and recover after migrating through the prey-limited Discovery Islands and Johnstone Strait region requires further investigation. This will help us to further compartmentalize the regional conditions juvenile salmon experience in their early marine phase.

In 1983, two trawl surveys were conducted in Discovery Passage and the surrounding channels and found that pink and chum abundance peaked in late June (Levings and Kotyk 1983). We observed peak pink and chum migration timing to be June 14, up to a week earlier than observed in 1983. However, the direct comparison of these estimates and the interpretation of statistics in this report are subject to some unknown degree of bias as a result of gear selectivity, and potentially non-random distributions of fish lengths in the habitats sampled. This highlights the need for quantification of the fine-scale distribution and habitat use by juvenile salmon along a gradient of depth and distance from shore. This will better our understanding of the representativeness and comparability of common sampling methods used to describe juvenile salmon populations migrating through coastal channels.

The Hakai Institute Juvenile Salmon Program has now captured the entire four-year life cycle of Fraser River sockeye salmon, two years of odd-year dominant pink juveniles, and four years of chum migrations. However, we have only observed the early marine conditions experienced by a genetically distinct community of co-migrating salmon, four separate times. Each annual observation between 2015 and 2018 is a unique cohort of sockeye genetic stocks, and pink, chum, coho and herring proportions. Replicated observations of sockeye genetic cohorts will be possible beginning May 2019, when we observe the same sockeye genetic cohort, we observed in 2015.

Finally, it is important to acknowledge that anomalous atmospheric and ocean conditions have dominated the last four years, and our data collected since 2015 reflect that. Ongoing research will reveal the extent of the juvenile salmon response to conditions in the preceding years. Furthermore, as adult salmon return from the high seas, having experienced these anomalous conditions, we will gain a better understanding of what the overall impact to salmon productivity will be. As we continue to disentangle the web of local and global weather and climate interactions, we will be able to identify how those processes interact and drive the key factors influencing early marine survival of Pacific salmon.

\section{Data}

The data used for this analysis is available at https://doi.org/10.21966/99MG-0S52. Some of the models and methods used to produce our time-series statistics and visualizations for this program will undergo ongoing development as we seek to improve the accuracy of current estimates, incorporate historical observations from other organizations, and add new variables to our annual observations. The development of our annual observations data, code, and analyses can be observed and contributed to from our code and data repository at https://github.com/HakaiInstitute/jsp-time-series. An interactive data explorer tool for this developing time series can be accessed online at http://hecate.hakai.org/shiny/JSP/.

\section{REFERENCES}

Beamish, R., and C. Mahnken. 2001. A critical size and period hypothesis to explain natural regulation of salmon abundance and the linkage to climate and climate change. Progr. Oceanogr. 49: 423-37.

Beamish, R., C. Neville, R. Sweeting, and K. Lange. 2012. The synchronous failure of juvenile Pacific salmon and herring production in the Strait of Georgia in 2007 and the poor return of sockeye salmon to the Fraser river in 2009. Mar. Coast. Fish. 4 (1): 403-14. doi.org/10.1080/19425120.2012.676607.

Chandler, P.C. 2019. Sea-surface temperature and salinities at B.C. lighthouses. Oral presentation at State of the Pacific Ocean meeting. March 18-19, 2019. Sidney, British Columbia, Canada. 
Chandler, P.C., S.A. King, and J. Boldt. 2017. State of the Physical, Biological and Selected Fishery Resources of Pacific Canadian Marine Ecosystems in 2016. Can. Tech. Rep. Fish. Aquat. Sci. 3225: 243 + vi.

Chandler, Peter C., S.A. King, and J. Boldt. 2018. State of the Physical, Biological and Selected Fishery Resources of Pacific Canadian Marine Ecosystems in 2013. Can. Tech. Rep. Fish. Aquat. Sci. 3102: vi + 136.

Cleveland, W.S., E. Grosse, and W.M. Shyu. 1992. Local regression models. Chapter 8 of Statistical Models in S eds J.M. Chambers and T.J. Hastie, Wadsworth \& Brooks/Cole.

Cohen, B. 2012. Cohen Commission of Inquiry into the Decline of Sockeye Salmon in the Fraser River. The Uncertain Future of Fraser River Sockeye. Volume 3: Recommendations-Summary - Process. Publishing and Depository Services, Vancouver, B.C. 203 pp. .

Godwin, Sean C, L.M., Dill, J.D. Reynolds, and M. Krkosek. 2015. Sea Lice, sockeye salmon, and foraging competition: lousy fish are lousy competitors. Can. J. Fish. Aquat. Sci. 1120: 778-82. doi.org/10.1139/cjfas2014-0284.

Groot, C., K. Cooke, G. Ellis, and R. Bailey. 1985. Data record of juvenile sockeye salmon and other fish species captured by purse seine and trawl in the Strait of Georgia, Johnstone Strait and Queen Charlotte Strait in 1982, 1983, 1984, and 1985. Canadian Data Report of Fisheries and Aquatic Sciences No. 561.

Heard, W.R. 1991. Life history of pink salmon. In Pacific salmon life histories. Edited by C. Groot and L. Margolis. Univ. British Columbia Press, Vancouver. pp. 119-230.

Hunt, B.P.V., B.T. Johnson, S.C. Godwin, M. Krkošek, E.A. Pakhomov, and L. Rogers. 2018. The Hakai Institute Juvenile Salmon Program: Early Life History Drivers of Marine Survival in Sockeye, Pink and Chum Salmon in British Columbia. Institute for the Oceans; Fisheries; Department of Earth, Ocean; Atmospheric Sciences, Univ. British Columbia, Hakai Institute, Earth to Ocean Research Group, Simon Fraser Univ., Department of Ecology; Evolutionary Biology, Univ. Toronto.

Johnson, B.T, C.L. Julian, G.C. V. Janusson, and B.P.V. Hunt. 2018. Juvenile Salmon Migration Dynamics in the Discovery Islands and Johnstone Strait. N. Pac. Anadr. Fish Comm. Doc. 1790. 10 pp. (Available at https://npafc.org)

Johnson, B.T, J.C.L. Gan, S.C. Godwin, M. Krkosek, and B.P.V. Hunt. 2019. Juvenile Salmon Migration Observations in the Discovery Islands and Johnstone Strait in British Columbia, Canada in 2018. N. Pac. Anadr. Fish Comm. Doc. 1838. 21 pp. (Available at https://npafc.org)

LeBrasseur, R. J., and R.R. Parker. 1964. Growth Rate of Central British Columbia Pink Salmon (Oncorhynchus gorbuscha). Fish. Res. Board. Can. 21 (5): 1101-1128.

Levings, C.D., and M. Kotyk. 1983. Results of Two Boat Trawling for Juvenile Salmonids and Nearby Channels, Northern Strait of Georgia. Canadian Manuscript of Fisheries; Aquatic Sciences-Fisheries; Oceans Canada.

Margolis, L., G.W. Esch, A.M. Kuris, and G.A. Schad. 1990. The Use of Ecological Terms in Parasitology (Report of an Ad Hoc Committee of the American Society of Parasitologists). J. Parasitol. 68(1): 131-33. doi.org/10.2307/3281335.

McKinnell, S., E. Curchitser, K. Groot, M. Kaeriyama, and M. Trudel. 2014. Oceanic and atmospheric extremes motivate a new hypothesis for variable marine survival of Fraser River sockeye salmon. Fish. Oceanogr. 23: 322-341.

McQueen, D., and D. Ware. 2006. Handbook of Physical, Chemical, Phytoplankton, and Zooplankton Data from Hecate Strait, Dixon Entrance, Goose Island Bank and Queen Charlotte Sound. Fisheries and Oceans Canada Data Report of Fisheries and Oceans Canada. Nanaimo, BC, Canada.

Neville, C., S. Johnson, T. Beacham, T. Whitehouse, J. Tadey, and M. Trudel. 2016. Initial Estimates from an Integrated Study Examining the Residence Period and Migration Timing of Juvenile Sockeye Salmon from the Fraser River through Coastal Waters of British Columbia. N. Pac. Anadr. Fish Comm. Bull. 6: 45-60. (Available at https://npafc.org)

Neville, C., M. Trudel, R.J. Beamish, and S.C. Johnson. 2013. The early marine distribution of juvenile sockeye salmon produced from the extreme low return in 2009 and the extreme high return in 2010.

Peterman, R.M., D. Marmorek, B. Beckman, M. Bradford, M. Lapointe, N. Mantua, B. Riddell, M. Scheuerell, M. Staley, K. Wiechowski, J. Winton, and C. Wood. 2010. Synthesis of evidence from a workshop on the decline of Fraser River sockeye. June 15-17, 2010. A Report to the Pacific Salmon Commission. Vancouver, B.C., 123 pp. +35 pp. of appendices.

Preikshot, D., R.J. Beamish, R.M. Sweeting, C.M. Neville, and T.D. Beacham. 2012. The residence time of juvenile Fraser river sockeye salmon in the strait of Georgia. Mar. Coast. Fish. 4(1): 438-449.

R Core Team. 2017. R: A Language and Environment for Statistical Computing. Vienna, Austria: R Foundation for Statistical Computing. (Available at https://www.R-project.org/) 